\title{
Definition of sampling units begets conclusions in ecology: the case of habitats for plant communities
}

Martin A Mörsdorf, Virve T. Ravolainen, Leif Einar Støvern, Nigel G. Yoccoz, Ingibjörg S. Jónsdóttir, Kari Anne Bråthen In ecology, expert knowledge on habitat characteristics is often used to define sampling units such as study sites. Ecologists are especially prone to such approaches when prior sampling frames are not accessible. Here we ask to what extent can different approaches to the definition of sampling units influence the conclusions that are drawn from an ecological study? We do this by comparing a formal versus a subjective definition of sampling units within a study design which is based on well-articulated objectives and proper methodology. Both approaches are applied to tundra plant communities in mesic and snowbed habitats. For the formal approach, sampling units were first defined for each habitat in concave terrain of suitable slope using GIS. In the field, these units were only accepted as the targeted habitats if additional criteria for vegetation cover were fulfilled. For the subjective approach, sampling units were defined visually in the field, based on typical plant communities of mesic and snowbed habitats. For each approach, we collected information about plant community characteristics within a total of 11 mesic and seven snowbed units distributed between two herding districts of contrasting reindeer density. Results from the two approaches differed significantly in several plant community characteristics in both mesic and snowbed habitats. Furthermore, differences between the two approaches were not consistent because their magnitude and direction differed both between the two habitats and the two reindeer herding districts. Consequently, we could draw different conclusions on how plant diversity and relative abundance of functional groups are differentiated between the two habitats depending on the approach used. We therefore challenge ecologists to formalize the expert knowledge applied to define sampling units through a set of well-articulated rules, rather than applying it subjectively. We see this as instrumental for progress in ecology as only rules based on expert knowledge are transparent and lead to results reproducible by other ecologists. 
2 Martin A. Mörsdorf ${ }^{1,2,3}$, Virve T. Ravolainen ${ }^{2,4}$, Leif Einar Støvern ${ }^{5}$, Nigel G. Yoccoz ${ }^{2}$, Ingibjörg Svala

3 Jónsdóttir ${ }^{1,3}$, Kari Anne Bråthen²

$4 \quad{ }^{1}$ Department of Life and Environmental Sciences, University of Iceland, Reykjavík, Iceland

$5 \quad{ }^{2}$ Department of Arctic and Marine Biology, The Arctic University of Norway, Tromsø, Norway

$6 \quad{ }^{3}$ Department of Arctic Biology, University Centre in Svalbard UNIS, Longyearbyen, Norway

$7 \quad{ }^{4}$ Norwegian Polar Institute, Tromsø, Norway

$8 \quad{ }^{5}$ Norwegian Institute for Forest and Landscape Research, Tromsø, Norway

9 Corresponding author:

10 Martin A. Mörsdorf

11 Sturlugata, 7

12101 Reykjavík-IS

13 Phone: +354-7756957

14 e-mail: $\underline{\text { mam28@hi.is }}$ 


\section{Introduction}

16 Sampling in ecology can be challenging. Ecological systems are characterized by complexity (Loehle,

17 2004) about which there is a paucity of information (Carpenter, 2002). Hence, ecological sampling is

18 often accompanied by unknown characteristics that may unintentionally cause estimates to be

19 dependent on the sampling designs, even to the extent that they "beget conclusions", as was shown for

20 the impact of the Exxon Valdez oil spill (Peterson et al., 2001; Peterson et al., 2002). The bases for

21 achieving unbiased estimates are study- or sampling designs that include well-articulated objectives

22 along with proper methodology (Olsen et al., 1999; Yoccoz et al., 2001; Albert et al., 2010). In

23 addition, sampling designs need to be transparent, enabling others to repeat the study. Accordingly,

24 ecologists have been encouraged to use formal approaches (Legendre et al., 2002; Edwards et al. 2005,

25 Edwards et al., 2006; Albert et al., 2010). However, whilst sources of bias and a call for formal rules in

26 sampling designs have received attention, the seemingly simple task of defining a sampling unit, such

27 as a study site, also merits thorough consideration, especially in community ecology. Indeed, the

28 definition of sampling units is often a task that demands expert knowledge. Expert knowledge can be

29 applied in such a way that sampling units are formally defined but in ecology, expert knowledge

30 implies often a subjective definition of sampling units before data collection is initiated (Whittaker et

31 al., 1973; Kenkel et al.,1989; Franklin et al., 2002; Loehle, 2004; McBride \& Burgman, 2012).

In situations where sampling units are not clearly defined, the availability of relevant sampling

33 units is not known before entering the field, i.e. there is no well-defined sampling frame and in its

34 vacancy, a subjective definition of sampling units is applied in order to guide sampling to ecological

35 units that are determined to be suitable in the field. In principle, the selection of any subjectively

36 defined sampling unit can never be sufficiently articulated as to enable other researchers to repeat the

37 study, or to allow generalizations of results to a specific target population (in a statistical sense) (Olsen 
38 et al., 1999; Schreuder, Gregoire \& Weyer, 2001). Moreover, in phytosociological studies it has been

39 documented that individual preferences in selecting sampling units that were defined subjectively can

40 lead to biased estimates (Chytrý, 2001; Botta-Dukát et al., 2007; Hédl, 2007). The criticism of using a

41 subjective definition of sampling units is both theoretically and empirically based, but it may merely

42 reflect a study-specific bias between subjective and more formal approaches. Therefore, in this study,

43 we want to compare a subjective versus a formal definition of sampling units in the same study system

44 in order to assess whether subjective definition merely introduces bias, overstating findings, or if the

45 way of defining sampling units even begets conclusions.

Studies that have compared formal versus subjective sampling have investigated sampling units

based on existing geographical data (e.g. Edwards et al., 2006; Hédl, 2007; Michalcová et al., 2011). A

48 formal a priori definition of sampling unit criteria could therefore be done before sampling was

49 initiated. However, ecologists might often not have access to such data which is especially the case

50 when the spatial extent of sampling units is smaller than the spatial resolution of previously existing

51 geographical data (Roleček et al., 2007). As a way of making the definition of units more transparent in

52 such situations, a few studies used formal criteria for suitable sampling units that are defined a priori to

53 the field sampling (e.g. Ravolainen et al., 2010).

Habitats are perhaps some of the most difficult sampling units to define (Whittaker et al., 1973;

55 Franklin et al., 2002), but are central to many conservation programs such as the "European council

56 directive on the conservation of natural habitats and of wild fauna and flora" (FFH) (Anon, 1992) or

57 the International Union for Conservation of Nature (IUCN) Red List of Threatened Species (IUCN,

58 2013). Despite the acknowledged importance of habitats, definitions differ greatly among conservation

59 programs worldwide. Whereas some conservation initiatives rely on formal definitions of habitat

60 criteria (Jeffers, 1998; Jongman et al., 2006), others rely on a subjective definition of habitats in the 
61 field (Jennings et al., 2009). In this paper, we focus on habitats and address the question of whether

62 subjective or formal definitions of sampling units lead to different estimates of habitat properties. We

63 therefore compared a formal approach, where the final selection of these habitats involved an a priori

64 definition of sampling units, to an approach involving only a subjective definition (sensu Gilbert, 65 1987).

For both approaches we aimed at two habitats typical for tundra. These habitats are

67 characterized by their difference in growing conditions and are found in sloping, concave terrain. Here,

68 slopes of intermediate steepness provide intermediate moisture conditions (mesic habitats) and gently

69 inclined slopes have wetter conditions combined with a long lasting snow cover (snowbed habitats)

70 (Fremstad, 1997). For the formal approach of defining sampling units, we used explicit criteria of the

71 aforementioned habitat terrain and a terrain model in order to extract a list of potential sampling units.

72 Because we expected that some of these would not be suitable for sampling (e.g. because of boulder

73 fields), we pre-defined additional habitat criteria to be applied in the field. For the subjective approach

74 of defining sampling units, habitats were solely subjectively selected in the field. Both approaches

75 were applied within the same sampling design that ensured balanced sampling with respect to major

76 ecological gradients.

The research question, i.e. what are the plant community characteristics that describe mesic and snowbed habitats, and the measurement of plant community characteristics, were the same in both approaches. For all sampling units, estimates of standing crop of the most abundant plant species and

80 plant functional groups were assessed as well as within plant community diversity. Finally, to evaluate

81 whether different approaches to defining sampling units lead to different estimates of habitat

82 properties, we tested the effect of using formal versus subjective definition of sampling units on the

83 estimates of these plant community characteristics. 


\section{Materials and Methods}

\section{Ecosystem Characteristics}

87 The field sampling for the current study was conducted during peak growing season between $20^{\text {th }}$ and

$8830^{\text {th }}$ of July 2011 on Varanger Peninsula, the north-eastern part of Finnmark County in northern

89 Norway (Fig. 1A). The Varanger Peninsula is delineated by the Barents Sea towards the north and

90 birch forests towards the south. Sandstone, sandstone intermingled with schist, and sandstone

91 intermingled with schist and calcareous bedrock are among the most common geological parental

92 materials (The Geological survey of Norway; www.ngu.no). The topography is characterized by a

93 mixture of plateaus and gently sloping hills (maximum height of approximately $500 \mathrm{~m}$ ) that are

94 intersected by river valleys. The plateaus build a border with steep slopes towards the Barents Sea.

95 During the growing season (July to August) average (monthly) precipitation is $47.7 \mathrm{~mm}$ (range 38 - 55

$96 \mathrm{~mm}$ ) and temperature is $8.7^{\circ} \mathrm{C}$ (range $\left.6.2-10.5^{\circ} \mathrm{C}\right)(30$ year averages from 1960 to 1990 , Norwegian

97 Meteorological Institute, www.met.no).

98 We conducted our study in the low alpine zone. The vegetation of the low alpine zone in this

99 region is generally classified as low shrub tundra (Walker et al., 2005) with mountain birch (Betula

100 pubescens Ehrh.) forming the tree line (Oksanen \& Virtanen, 1995). Topography affecting snow

101 accumulation and moisture conditions creates habitats that are differentiated into exposed ridges, and

102 steep and gentle parts of slopes, creating a sequence from xeric to mesic and very moist conditions

103 with increasing duration of snow cover (Fremstad, 1997). These habitat characteristics give rise to

104 distinct vegetation types such as ridge, mesic and snowbed vegetation (Fremstad, 1997). In this study

105 we targeted mesic and snowbed habitats. Commonly occurring plant species in mesic habitats on the

106 Varanger Peninsula include tall stature forbs (e.g. Alchemilla spp., Geranium sylvaticum L., 
107 Ranunculus acris L., Rhodiola rosea L.) in combination with grasses (e.g. Phleum alpinum L., Poa

108 pratense ssp. alpigena (Fr.) Hiit., Festuca rubra L.). Snowbed habitats are characterized by prostrate

109 Salix species (Salix herbacea L.) in combination with other grasses (e.g. Festuca rubra L., Poa alpina

110 L.) and forbs (e.g. Cerastium sp.) of lower stature. Mosses such as Dicranum spp. or Polytrichum spp.

111 are also prevalent here.

112 Semi domesticated reindeer (Rangifer tarandus L.) that are managed by indigenous Sami

113 people are the most common large herbivores in eastern Finnmark. In summer, reindeer herds are kept

114 in the coastal mountains in large districts, which range in area from about 300 to $4000 \mathrm{~km}^{2}$, with most

115 reindeer migrating inland during winter. Densities of reindeer have increased during the past two

116 decades in some of these summer grazing districts, whilst remaining constant in others (see Table 2 in

117 Ravolainen et al., 2010). This was evident on Varanger Peninsula during the period of our study, with

118 contrasting reindeer densities observed in the two neighboring districts (Fig. 1). Other large herbivores

119 present on Varanger peninsula are moose (Alces alces L.) and locally occurring domestic sheep (Ovis

120 aries L.). Ptarmigans (Lagopus lagopus L.) and Lagopus muta (Montin), Norwegian lemming

121 (Lemmus lemmus L.), root vole (Microtus oeconomus Pallas) and grey-sided vole (Myodes rufocanus

122 Sund.) are also found in the area (Henden et al., 2011).

\section{Sampling design}

125 We employed a hierarchical, nested sampling design. Our protocol for selecting sampling units that 126 corresponded to the habitats of interest involved several levels of selection (Fig. 1). Using the Varanger

127 Peninsula as the sampling region (Fig. 1A) we covered both districts of contrasting reindeer density.

128 We used information retrieved from a digital elevation model (DEM) to locate landscape areas that had 129 potential sampling units representing the habitats of interest: Using GIS (ESRI ArcGIS with ArcMap.

130 Version 8.3.0) we placed a raster of $2 \times 2 \mathrm{~km}$ landscape areas over a $25 \times 25 \mathrm{~m}$ pixel DEM (produced 
131 by Norwegian Mapping Authorities on the basis of elevation contour lines) covering the entire

132 peninsula (Fig. 1A). Potential sampling units needed to have at least two $25 \times 25 \mathrm{~m}$ neighboring pixels

133 of concave topography with a mean slope between $5^{\circ}$ and $30^{\circ}$. We restricted sampling to units that

134 were a minimum distance of $500 \mathrm{~m}$ from birch forests and to an altitude of below $350 \mathrm{~m}$ above sea

135 level in order to stay within the low alpine tundra. Finally we avoided lakes, glaciers, major roads and

136 power lines, and only considered units that were within a one day's walking distance from a road in

137 order to be accessible. We then only selected landscape areas that according to the DEM included at

138 least three potential sampling units that followed these criteria. This limited us to a total of 21

139 landscape areas over the whole peninsula. Out of time constraints we ultimately sampled nine of these

140 landscape areas, divided between the two reindeer districts and with a good geographic spread (Fig.

141 1A).

Within each landscape area, the selection of sampling units was based on two different

143 approaches of defining them (Fig. 1B). In the first approach (formal approach), we applied expert

144 knowledge by defining a priori criteria in two steps. First we defined topographical criteria to locate

145 habitats in GIS (as described above). The spatial resolution of our DEM was however too coarse for an

146 a priori distinction of the two target habitats. Therefore, secondly, we defined additional criteria to be

147 evaluated in the field. Here, the sampling unit had to show characteristics indicating both target

148 habitats (i.e. mesic and snowbed) to be present. This criterion corresponded to a visible shift in plant

149 species composition. In addition, the visually estimated vegetation cover had to be higher than $75 \%$,

150 and the habitat's grain size had to be large enough to include a minimum of two transects for

151 vegetation measurements (with at least one transect having a length of $10 \mathrm{~m}$ and every transect being 5

$152 \mathrm{~m}$ apart; see more details below). If a potential sampling unit failed to meet any of these criteria, it was

153 discarded and the next most accessible potential sampling unit was visited and inspected for possible 
154 field analyses. The sampling units of the formal approach correspond to the sampled habitats in

155 González et al. (2010) and Ravolainen et al. (2010).

156 In the second approach (subjective approach), we based the selection of sampling units on a

157 subjective definition as follows. As we entered the landscape areas we subjectively assessed

158 topography to locate sloping, concave terrain for the habitats of interest. When a typical plant

159 community that either indicated a mesic or a snowbed habitat was found, it was considered as part of a

160 sampling unit and it was analyzed as long as habitat size complied to the additional field criteria used

161 in the formal approach (i.e. a vegetation cover of minimum $75 \%$ over a habitat area large enough to

162 include a minimum of two transects with at least one of them being $10 \mathrm{~m}$ long and each transect being

163 horizontally spaced $5 \mathrm{~m}$ apart from each other). For both approaches the final study unit was delineated

164 either by convex areas of heath vegetation or a maximum transect length of $50 \mathrm{~m}$.

Sometimes we sampled two sampling units per approach within one landscape area, in which

167 case the closest set of sampling units, i.e. one from each of the two approaches, were termed "study

168 area" being nested within landscape area (Fig. 1B).

\section{Measurement of plant community characteristics}

171 Within each selected habitat, measurement of plant community characteristics was identical for both

172 approaches, except for the placement of transects. In the formal approach, the starting point of each

173 transect was given by the initial GPS coordinates and in the subjective approach starting points were

174 chosen subjectively so that transects would cover the longest spatial extent of the targeted habitats (Fig.

175 1C). For both approaches each transect was marked with a measuring tape running downslope from the

176 starting point with $5 \mathrm{~m}$ in horizontal distance between transects. Depending on the spatial extent of the

177 habitats, we sampled between 2 and 5 transects with lengths varying from $4 \mathrm{~m}$ to $32 \mathrm{~m}$. Thereafter, we 
178 recorded plant species abundance using the point intercept method according to Bråthen \& Hagberg

179 (2004). A frame of $40 \mathrm{~cm} \times 40 \mathrm{~cm}$ with 5 pins of $2 \mathrm{~mm}$ diameter attached, one to each of the four

180 frame corners and one to the center (see Ravolainen et al., 2010), was placed at fixed intervals of $2 \mathrm{~m}$

181 along the measuring tape..For each placement of the frame (i.e. for each plot), intercepts between pins

182 and above ground vascular plant parts were recorded for each species separately. Species within the

183 frame that were not hit by a pin were recorded with the value of 0.1 . Table 1 presents a list of

184 replication of all study units according to the spatial hierarchy of our design.

185

186 Response variables for data analyses

187 We converted point intercept data into biomass [g/plot] using weighted linear regression (Bråthen \&

188 Hagberg, 2004) and established calibration models (see Table S1 in Ravolainen et al. 2010), after

189 which plant community measures were calculated for each plot in the data set. First we calculated three

190 commonly used measures of within community (alpha-) diversity (Gini-Simpson index, Shannon

191 entropy and Species Richness). Then we calculated biomass of the most dominant species (Betula nana

192 L., Empetrum hermaphroditum Hagerup. and Vaccinium myrtillus L.) and biomass of plant functional

193 groups (as in Bråthen et al., 2007). Certain plant functional groups such as hemi-parasites had very low

194 abundance and were therefore merged into the group of forbs (Table 2). Species and plant functional

195 groups differed between the two habitats of interest, reflecting the fact that the mesic and the snowbed

196 habitats were generally different in their species composition.

\section{Statistical analysis}

199 We analyzed the three measures of (within-) community diversity and the biomass of different species

200 and plant functional groups as response variables separately for each habitat type. When fitting linear

201 mixed effect models, the approach to defining sampling units (formal versus subjective), the reindeer 
202 district (east versus west) and their interaction were used as fixed factors in the models. Bedrock type

203 was included as a factor with three levels (sandstone; sandstone intermingled with schist; sandstone

204 intermingled with schist and calcareous rock) and used as a co-variate (Table S2 of the supplemental

205 information). The landscape areas and the study areas were set as random factors to account for spatial

206 autocorrelation within areas. For some of the response variables we had to exclude study areas from the

207 random effects structure because data existed for one study area per landscape area only. Models that

208 had biomass of dominant plant species or biomass of functional groups as response variable were $\log _{\mathrm{e}}$

$209(\mathrm{x}+\mathrm{v})$ transformed in order to assure model assumptions, with $(\mathrm{v})$ representing the smallest biomass

210 value of the sampled data in order to avoid negative values for plots with zero abundance. Diversity

211 measures were not transformed. We used standard diagnostics to assess constancy and normality of

212 residuals and controlled for outliers. All models were run using the lme function as part of the nlme

213 package (Pinheiro et al., 2012) in R (version 2.12.1; The R Foundation for Statistical Computing ). A

214 list of all models, containing Akaike's Information Criterion and test statistics for the used fixed

215 factors, can be found in the supplemental information (Tables S3, S4).

216

217 Results

218 Mesic habitat

219 The approach to defining sampling units affected almost all estimates of plant community diversity in

220 the mesic habitat (Fig.2A, B, C). The estimates of the diversity indices were in most cases significantly

221 higher in the subjective compared with the formal approach. However, for one of the indices (Gini-

222 Simpson), estimates were only higher in the western district (Fig.2A).

223 Estimates of plant functional group biomass and biomass of dominant plant species were

224 significantly different between the two approaches (Fig. 2D). The biomass of forbs was estimated to be 
225 consistently higher when using the subjective approach in both districts. However, there were

226 interaction effects between the approach type and the reindeer district. For many response variables,

227 differences between the two approaches were only significant in one of the two districts (prostrate

228 Salix, grasses, evergreens, deciduous woody species, Vaccinium myrtillus, Empetrum

229 hermaphroditum). Biomass estimates of other response variables (silica rich grasses and Betula nana)

230 were lower in the eastern, but higher in the western district when the subjective approach was used.

\section{Snowbed habitat}

233 The approach to defining sampling units also had significant effects on the diversity estimates for the

234 snowbed habitat (Fig.3A, B, C). For both Shannon entropy and Species Richness, the subjective

235 approach revealed higher estimates in the eastern but lower estimates in the western district (Fig.3B,

236 C).

Significant differences between the two approaches were also found for the biomass estimates

238 of dominant plant species and of different plant functional groups (Fig.3D). Similar to the mesic

239 habitat, there were significant interaction effects between the approach to define sampling units and the

240 reindeer district. Biomass estimates of some plant functional groups were only affected by the

241 approach in one of the two districts (forbs, grasses. silica rich grasses). For prostrate Salix, we found

242 opposite effects of the approach between the two districts. The biomass was estimated to be

243 significantly lower in the eastern, but significantly higher in the western district when using the

244 subjective approach.

\section{Discussion}


247 Differences in defining sampling units affect community estimates depending on ecological context

249 In our study, the sampling approach based on a subjective definition of sampling units revealed 250 significant effects on many of our response variables in comparison to the approach based on formal 251 rules.

252 For instance, from our subjective approach our conclusion would be that mesic and snowbed 253 habitats had very low but comparable biomass of silica rich grasses within the two reindeer districts 254 where data were collected. In contrast, our results based on a formal definition of sampling units show a considerably higher abundance of silica rich grasses in the eastern district where also reindeer density

256 is higher. The role of silicate rich plants in plant herbivore interactions (Vicari \& Bazely, 1993)

257 indicate that the acceptance of one conclusion or the other could lead to very different ecological outcomes and highlight the need for careful consideration in the definition of sampling units in ecological studies. Hence, the way sampling units were defined begets ecological conclusions to be drawn (Peterson et al., 2001).

Previous studies have documented how individual preferences for certain sampling units could result in biased estimates, with for instance higher estimates of species richness compared to probabilistic sampling approaches (Chytrý, 2001; Botta-Dukát et al., 2007; Diekmann et al., 2007).

264 However, the subjective selection in this study only rendered constantly higher estimates of species richness in the mesic habitats, while species richness in the snowbed habitats was only increased by the subjective approach in the eastern district. We can only speculate on the reasons for this lack of consistency. For the mesic habitat, the consistently higher estimates of species richness in the subjective approach might be due to the fact that we focused on habitats with many indicator species that can be easily distinguished visually, such as different forb species (see Fig. 2D). Such a preference could also explain the higher estimates of species richness and forbs of snowbeds in the eastern district, 
271 where high reindeer abundance might lead to generally low abundance of facilitating plant species such

272 as forbs (Bråthen et al., 2007). The lower species richness estimates of the snowbed habitat in the

273 western district might be due to a preference of the sampling units that were visually more strongly

274 impacted by snow, causing a higher probability of selecting for late snowbeds as opposed to earlier

275 snowbeds. Late emergence from snow causes marginal growing conditions for vascular plants and

276 reduced species richness (Björk \& Molau, 2007). However, the fact that these interpretations would

277 only account for one specific district shows that the bias caused by the subjective definition of

278 sampling units in species richness depends on ecological context. We found similar context

279 dependencies for other diversity indices and for many of the biomass response variables in our study

280 (Fig. 2 and Fig. 3).

282 How to define sampling units to ensure comparability between studies?

283 Context dependency of the differences in estimates between the two approaches could also have

284 relevance to the comparability of ecological studies. Idiosyncratic results from work on similar study

285 systems are often found in ecological research (Chase et al., 2000; Hedlund et al., 2003; Badano \&

286 Cavieres, 2006). Our results indicate that idiosyncratic results within studies or among different studies

287 may have their roots in the way sampling units have been defined. With context dependency being one

288 of the greatest challenges of ecology today (Wardle et al., 2011), additional context dependency

289 enforced by the way ecological sampling units are defined will make it even more difficult to tackle

290 this challenge (see e.g. Franklin et al., 2002).

The definition of sampling units in our formal approach involved abiotic characteristics known

to represent the habitats in question (e.g. slope and curvature). Such terrain criteria were applied in a

293 way that allowed us to accurately document each sampling unit characteristic, although at the coarse

294 scale of the DEM. In contrast, we did not apply biotic criteria such as the usage of indicator plant 
295 species or indicator functional groups in an a priori way in this approach, for two reasons. First, plant

296 composition was largely unknown across the potential sampling units of the two habitats, reflecting the

297 absence of vegetation maps (at the grain size of our habitats) for the study area. Secondly, any

298 preference for plant indicators was likely to interfere with the outcome of our research question

299 (Ewald, 2003), i.e. what are the plant community characteristics of mesic and snowbed habitats?

300 However, because our focus was on plants, simple biotic criteria of vegetation cover and a visual shift

301 in type of plant community were not considered to interfere with our conclusions. Although the rules

302 applied in the formal approach were quite simple, they were considered relevant to the research

303 questions set. Clearly, more specific research questions would demand more refined formal rules.

304 For applications in ecology, the reproducibility of studies and the comparison between studies

305 are essential (Shrader-Frechette \& McCoy, 1994). Therefore, for any true comparison between studies

306 to be made, discrete sampling units such as habitats must be defined in the same way (Loehle, 2004).

307 Our study shows that even slight deviations in the definition of sampling units could affect the

308 comparability of results, even within the same study system. That is, only the formal approach to

309 defining sampling units is concomitantly transparent (i.e. by the set of formal rules applied), and

310 produced results that fulfill the premise on which further ecological understanding can be developed.

311 Hence, as sampling procedures that allow reproducibility and comparisons between studies are

312 essential, so are the sampling procedures to allow accumulation of ecological knowledge. We therefore

313 believe that the call for formal approaches in study designs (Legendre et al., 2002; Edwards et al.,

314 2005; Edwards et al., 2006; Albert et al., 2010) should also be extended to formal approaches to the

315 definition of sampling units.

316 The application of expert knowledge is a matter of discussion in several fields of ecology.

317 There are a number of studies that address ways of eliciting expert knowledge for decision making in

318 conservation or landscape ecology (Burgman et al., 2011; Martin et al., 2011; McBride \& Burgman, 
319 2012), including the use of expert opinion for modeling (Booker \& McNamara, 2004; Kuhnert et al.,

320 2010; Martin et al., 2011). In landscape ecology the use of expert knowledge has recently been

321 challenged to adhere to the same scientific rigor as other sampling approaches (Morgan, 2014). We

322 believe the application of expert knowledge deserves equal attention in terms of the definition of

323 sampling units, and especially in the definition of habitats, which should be done in a transparent way

324 (Whittaker et al., 1973; Franklin et al., 2002).

325

326 ACKNOWLEDGEMENTS

327 We are grateful to Geir Vie for his assistance during data collection in the field and to Coat (Climate-

328 Ecological Observatory of Arctic Tundra) for inspiration. 


\section{References}

331 Albert CH, Yoccoz NG, Edwards Jr TC, Graham CH, Zimmermann NE, Thuiller W. 2010. Sampling

332 in ecology and evolution - bridging the gap between theory and practice. Ecography 33: 1028-1037.

333 Anon, 1992. Council directive 92/43/EEC of 21 May 1992 on the conservation of natural habitats and

334 of wild fauna and flora. Official Journal of the European Communities.

335 Badano EI, Cavieres LA 2006. Ecosystem engineering across ecosystems: do engineer species sharing

336 common features have generalized or idiosyncratic effects on species diversity? Journal of

337 Biogeography 33: 304-313.

338 Björk RG, Molau U. 2007. Ecology of alpine snowbeds and the impact of global change. Arctic,

339 Antarctic, and Alpine Research 39: 34-43.

340 Booker JM, McNamara LA. 2004. Solving black box computation problems using expert knowledge

341 theory and methods. Reliability Engineering and System Safety 85: 331-340.

342 Botta-Dukát Z, Kovács-Láng E, Rédei T, Kertész M, Garadnai J. 2007. Statistical and biological

343 consequences of preferential sampling in phytosociology: Theoretical considerations and a case

344 study. Folia Geobotanica 42: 141-152.

345 Bråthen KA, Hagberg O. 2004. More efficient estimation of plant biomass. Journal of Vegetation

$346 \quad$ Science 15: 653-660.

347 Bråthen KA, Ims RA, Yoccoz NG, Fauchald P, Tveraa T, Hausner VH. 2007. Induced shift in

348 ecosystem productivity? Extensive scale effects of abundant large herbivores. Ecosystems 10: 773-

349789.

350 Burgman M, Carr A, Godden L, Gregory R, McBride M, Flander L, Maguire L. 2011. Redefining

351 expertise and improving ecological judgment. Conservation Letters 4: 81-87.

352 Carpenter SR. 2002. Ecological futures: Building an ecology of the long now. Ecology 83: 2069-2083.

353 Chase JM, Leibold MA, Downing AL, Shurin JB. 2000. The Effects of Productivity, herbivory, and 
plant species turnover in grassland food webs. Ecology 81: 2485-2497.

355 Chytrý M. 2001. Phytosociological data give biased estimates of species richness. Journal of

$356 \quad$ Vegetation Science 12: 441-444.

357 Diekmann M, Kühne A, Isermann M. 2007. Random vs non-random sampling: Effects on patterns of 358 species abundance, species richness and vegetation-environment relationships. Folia Geobotanica $359 \quad 42: 179-190$.

360 Edwards Jr TC, Cutler DR, Zimmermann NK, Geiser L, Alegria J. 2005. Model-based stratification for 361 enhancing the detection of rare ecological events. Ecology 86: 1081-1090.

362 Edwards Jr TC, Cutler DR, Zimmermann NE, Geiser L, Moisen GG. 2006. Effects of sample survey 363 design on the accuracy of classification tree models in species distribution models. Ecological 364 Modelling 199: 132-141.

365 Ewald J. 2003. A critique for phytosociology. Journal of Vegetation Science 14: 291-296.

366 Franklin AB, Noon BR, George L. 2002. What is habitat fragmentation? Studies in Avian Biology 25: $367 \quad 20-29$.

368 Fremstad E. 1997. Vegetasjonstyper i Norge. NINA Temahefte 12: 1-279.

369 Gilbert RO. 1987. Statistical methods for environmental pollution monitoring. New York: John Wiley 370 and Sons.

371 González VT, Bråthen KA, Ravolainen VT, Iversen M, Hagen SB. 2010. Large-scale grazing history 372 effects on arctic-alpine germinable seed banks. Plant Ecology 207: 321-331.

373 Hédl R. 2007. Is sampling subjectivity a distorting factor in surveys for vegetation diversity? Folia 374 Geobotanica 42: 1991-1998.

375 Hedlund, K, Regina IS, Van der Putten WH, Lepš J, Díaz T, Korthals GW, Lavorel S, Brown VK, 376 Gormsen D, Mortimer SR, Barrueco CR, Roy J, Smilauer P, Smilauerová M, Van Dijk C. 2003. 377 Plant species diversity, plant biomass and responses of the soil community on abandoned land 
across Europe: Idiosyncracy or above-belowground time lags. Oikos 103: 45-58.

379

380

Henden J-A, Ims RA, Yoccoz NG, Sørensen R, Killengreen ST. 2011. Population dynamics of tundra voles in relation to configuration of willow thickets in southern arctic tundra. Polar Biology 34: $533-540$.

IUCN 2013. The IUCN Red List of Threatened Species. Version 2013.2. Available at www.iucnredlist.org (accessed 21 November 2013).

Jeffers JNR. 1998. The statistical basis of sampling strategies for rivers: An example using river habitat survey. Aquatic Conservation: Marine And Freshwater Ecosystems 8: 447-454.

Jennings MD, Faber-Langendoen D, Loucks OL, Peet RK, Roberts D. 2009. Standards for associations and alliances of the U.S national vegetation classification. Ecological Monographs 79: 173-199.

Jongman RHG, Bunce RGH, Metzger MJ, Mücher CA, Howard DC, Mateus VL. 2006. Objectives and applications of a statistical environmental stratification of Europe. - Landscape Ecology 21: 409419

Kenkel NC, Juhász-Nagy P, Podani J. 1989. On sampling procedures in population and community ecology. Vegetatio 83: 195-207.

Kuhnert PM, Martin TG, Griffiths SP. 2010. A guide to eliciting and using expert knowledge in Bayesian ecological models. Ecology Letters 13: 900-914.

Legendre P, Dale MRT, Fortin M-J, Gurevitch J, Hohn M, Myers D. 2002. The consequences of spatial structure for the design and analysis of ecological field surveys. Ecography 25: 601-615.

Loehle C. 2004. Challenges of ecological complexity. Ecological Complexity 1: 3-6.

Martin TG, Burgman MA, Fidler F, Kuhnert PM, Low-Choy S, McBride M, Mengersen K. 2011. Eliciting expert knowledge in conservation science. Conservation Boilogy 26: 1-10.

McBride MF, Burgman MA. 2012. What is expert knowledge, how is such knowledge gathered, and how do we use it to address questions in landscape ecology? In: Perera AH, Drew CA, Johnson CJ 
eds. Expert knowledge and its application in landscape ecology. New York: Springer

403 Science+Business Media: 11-38.

404 Michalcová D, Lvoncík S, Chytrý M, Hájek O. 2011. Bias in vegetation databases? A comparison of 405 stratified-random and preferential sampling. Journal of Vegetation Science 22: 281-291.

406 Morgan MG. 2014. Use (and abuse) of expert elicitation in support of decision making for public 407 policy. Proceedings of the National Academy of Sciences of the United States of America 111: $408 \quad 7176-7184$.

409 Oksanen L, Virtanen R. 1995. Topographic, altitudinal and regional patterns in continental and sub410 oceanic heath vegetation of northern Fennoscandia. Acta Botanica Fennica 153: 1-80.

411 Olsen AR, Sedransk J, Edwards D, Gotway CA, Liggett W, Rathbun S, Reckhow K, Young L. 1999.

412 Statistical issues for monitoring ecological and natural resources in the United States. Environmental $413 \quad$ Monitoring and Assessment 54: 1-45.

414 Peterson CH, McDonald LL, Green RH, Erickson WP. 2001. Sampling design begets conclusions: the 415 statistical basis for detection of injury to and recovery of shore- line communities after the "Exxon 416 Valdez" oil spill. Marine Ecology Progress Series 210: 255-283.

417 Peterson CH, McDonald LL, Green RH, Erickson WP. 2002. The joint consequences of multiple 418 components of statistical sampling designs. Marine Ecology Progress Series 231: 309-314.

419 Pinheiro J, Bates D, DebRoy S, Sarkar D. 2012. nlme: Linear and nonlinear mixed effects models. R 420 package version 3.1-104.

421 Ravolainen VT, Yoccoz NG, Bråthen KA, Ims RA, Iversen M, González VT. 2010. Additive 422 partitioning of diversity reveals no scale-dependent impacts of large ungulates on the structure of 423 tundra plant communities. Ecosystems 13: 157-170.

424 Roleček, J, Chytrý M, Hájek M, Lvončik S, Tichý L. 2007. Sampling design in large-scale vegetation 425 studies: Do not sacrifice ecological thinking to statistical purism! Folia Geobotanica 42: 199-208. 
426 Schreuder HT, Gregoire TG, Weyer JP. 2001. For what applications can probability and non-

427 probability sampling be used? Environmental Monitoring and Assessment 66: 281-291.

428 Shrader-Frechette K, McCoy ED. 1994. Applied ecology and the logic of case studies. Philosophy of $429 \quad$ Science 61: 228-249.

430 Vicari M, Bazely DR. 1993. Do grasses fight back? The case for antiherbivore defences. Trends in $431 \quad$ Ecology and Evolution 8: 137-141.

432 Walker DA, Raynolds MK, Daniëls FJA, Einarsson E, Elvebakk A, Gould WA, Katenin AE, Kholod 433 SS, Markon CJ, Melnikov ES, Moskalenko NG, Talbot SS, Yurtsev BA, CAVM Team. 2005. The 434 circumpolar Arctic vegetation map. Journal of Vegetation Science 16. 267-282.

435 Wardle DA, Bardgett RD, Callaway RM, Van der Putten WH. 2011. Terrestrial ecosystem responses to 436 species gains and losses. Science 332: 1273-1277.

437 Whittaker RH, Levin SA, Root RB. 1973. Niche, habitat, and ecotope. The American Naturalist 107: $438 \quad 321-338$.

439 Yoccoz NG, Nichols JD, Boulinier T. 2001. Monitoring of biological diversity in space and time. $440 \quad$ Trends in Ecology and Evolution 16: 446-453. 
Table $\mathbf{1}$ (on next page)

Sample sizes presented for each of the hierarchical levels of the sampling design.

The sample sizes are presented for each of the hierarchical levels of the sampling design, for each of the two approaches and their summarized sample size. The formal and the subjective approach share samples at both levels above the level of sampling units. 


\begin{tabular}{|c|c|c|c|c|}
\hline & \multirow[t]{2}{*}{ nested hierarchy } & \multicolumn{3}{|c|}{ replication of units } \\
\hline & & formal & subjective & total for both approaches \\
\hline \multirow{4}{*}{ mesic habitat } & landscape area & 9 & 9 & 9 \\
\hline & study area & 11 & 11 & 11 \\
\hline & habitats/sampling units & 11 & 11 & 22 \\
\hline & transects & 30 & 25 & 55 \\
\hline \multicolumn{5}{|c|}{ 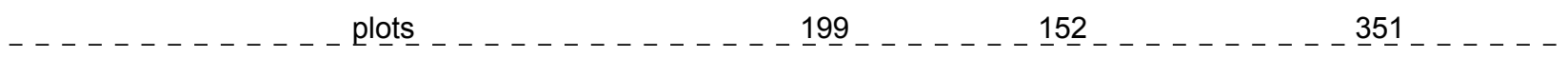 } \\
\hline \multirow{5}{*}{ snowbed habitat } & landscape area & 6 & 6 & 6 \\
\hline & study area & 7 & 7 & 7 \\
\hline & habitats/sampling units & 7 & 7 & 14 \\
\hline & transects & 18 & 16 & 34 \\
\hline & plots & 85 & 103 & 188 \\
\hline
\end{tabular}

3 
Table 2 (on next page)

Major plant functional groups and their associated species encountered in mesic and snowbed habitats.

The letters " $M$ " (mesic) and " $\mathrm{S}$ " (snowbed) indicate the occurrence of each species within the respective target habitat. The nomenclature follows the Pan Arctic Flora (http://nhm2.uio.no/paf/). 


\section{Forbs}

Alchemilla alpina $(\mathrm{M}, \mathrm{S})$

Antennaria alpina (M)

Antennaria dioica (M, S)

Bartsia alpina (M, S)

Bistorta vivipara $(\mathrm{M}, \mathrm{S})$

Caltha palustris (M)

Chamaepericlymenum suecicum (M)

Campanula rotundifolia (M, S)

Comarum palustre (M)

Draba glabella (M)

Epilobium anagallidifolium (S)

Epilobium hornemannii (M)

Euphrasia frigida $(\mathrm{M}, \mathrm{S})$

Euphrasia wettsteinii (M, S)

Geranium sylvaticum (M, S)

Geum rivale (M)

Listera cordata (M)

Melampyrum sylvaticum (M)

Omalotheca norvegica (M, S)

Omalotheca supina $(\mathrm{M}, \mathrm{S})$

Oxyria digyna (S)

Parnassia palustris (M, S)

Pedicularis lapponica (M, S)

Pinguicula vulgaris (M)

Potentilla crantzii (M)

Potentilla erecta (M)

\section{Grasses}

Ranunculus acris (M, S)

Rhodiola rosea (M, S)

Rubus chamaemorus (M, S)

Rumex acetosa (M, S)

Sagina saginoides (S)

Saussurea alpina (M, S)

Saxifraga cespitosa (M)

Sibbaldia procumbens (M, S)

Silene acaulis (M)

Solidago virgaurea $(\mathrm{M}, \mathrm{S})$

Stellaria nemorum (S)

Taraxacum croceum aggregate (M,

S)

Thalictrum alpinum (M, S) Silica rich grasses

Trientalis europaea (M, S) Deschampsia cespitosa (M, S)

Trollius europaeus (M, S) Nardus stricta (M, S)

Veronica alpina $(\mathrm{M}, \mathrm{S})$

Viola biflora (M, S)

Viola palustris $(\mathrm{M})$

Prostrate Salix species

Salix herbacea $(\mathrm{M}, \mathrm{S})$

Salix reticulata $(\mathrm{M})$

Festuca rubra (M, S)
Agrostis mertensii (M, S)

Anthoxanthum nipponicum (M, S)

Avenella flexuosa (M, S)

Calamagrostis neglecta (M, S)

Calamagrostis phragmitoides (M)

Festuca ovina (M, S)

Phleum alpinum (M, S)

Poa alpina (M, S)

Poa pratensis (M)

Vahlodea atropurpurea (M)

\section{Sedges/Rushes}

Carex aquatilis (S)

Carex bigelowii (M, S)

Carex brunnescens (M)

Carex canescens (M, S)

Carex lachenalii $(\mathrm{M}, \mathrm{S})$

Carex vaginata $(\mathrm{M}, \mathrm{S})$

Eriophorum angustifolium (M)

Eriophorum vaginatum (M)

Juncus arcticus (S)
Juncus filiformis (M, S)

Luzula multiflora $(\mathrm{M}, \mathrm{S})$

Luzula spicata (M, S)

Luzula wahlenbergii (S)

\section{Deciduous woody plants}

Arctous alpina (M)

Vaccinium uliginosum $(\mathrm{M}, \mathrm{S})$

\section{Evergreen woody plants}

Andromeda polifolia (M)

Dryas octopetala (M)

Harrimanella hypnoides (M, S)

Juniperus communis (M)

Kalmia procumbens (M, S)

Linnaea borealis (M)

Orthilia secunda $(\mathrm{M})$

Phyllodoce caerulea (M)

Pyrola minor (M, S)

Pyrola grandiflora (M, S)

Vaccinium vitis-idaea (M, S)

Dominant plant species

Betula nana (M, S)

Empetrum nigrum (M, S)

Vaccinium myrtillus (M, S) 


\section{1}

The figure represents the hierarchical nestedness of the sampling design.

(A) The figure shows the geographical location of the sampling region (Varanger Peninsula, northern Norway) and nestedness of the sampling design. The shades of gray delimit the districts of contrasting reindeer density. Open squares show the raster of $2 \times 2 \mathrm{~km}$ landscape areas where major roads, power lines, glaciers and large water bodies have been omitted. Black squares correspond to landscape areas that adhered to all other delimitations in our design (see Materials and Methods section for details). (B) One landscape area contained up to two study areas (dashed line) which inherited a pair of formally (GPS) and subjectively (eye) defined sampling units. (C) Each sampling unit contained both a mesic and a snowbed habitat. The recording of vegetation characteristics within each habitat was conducted along transects (dashed lines within habitats). 


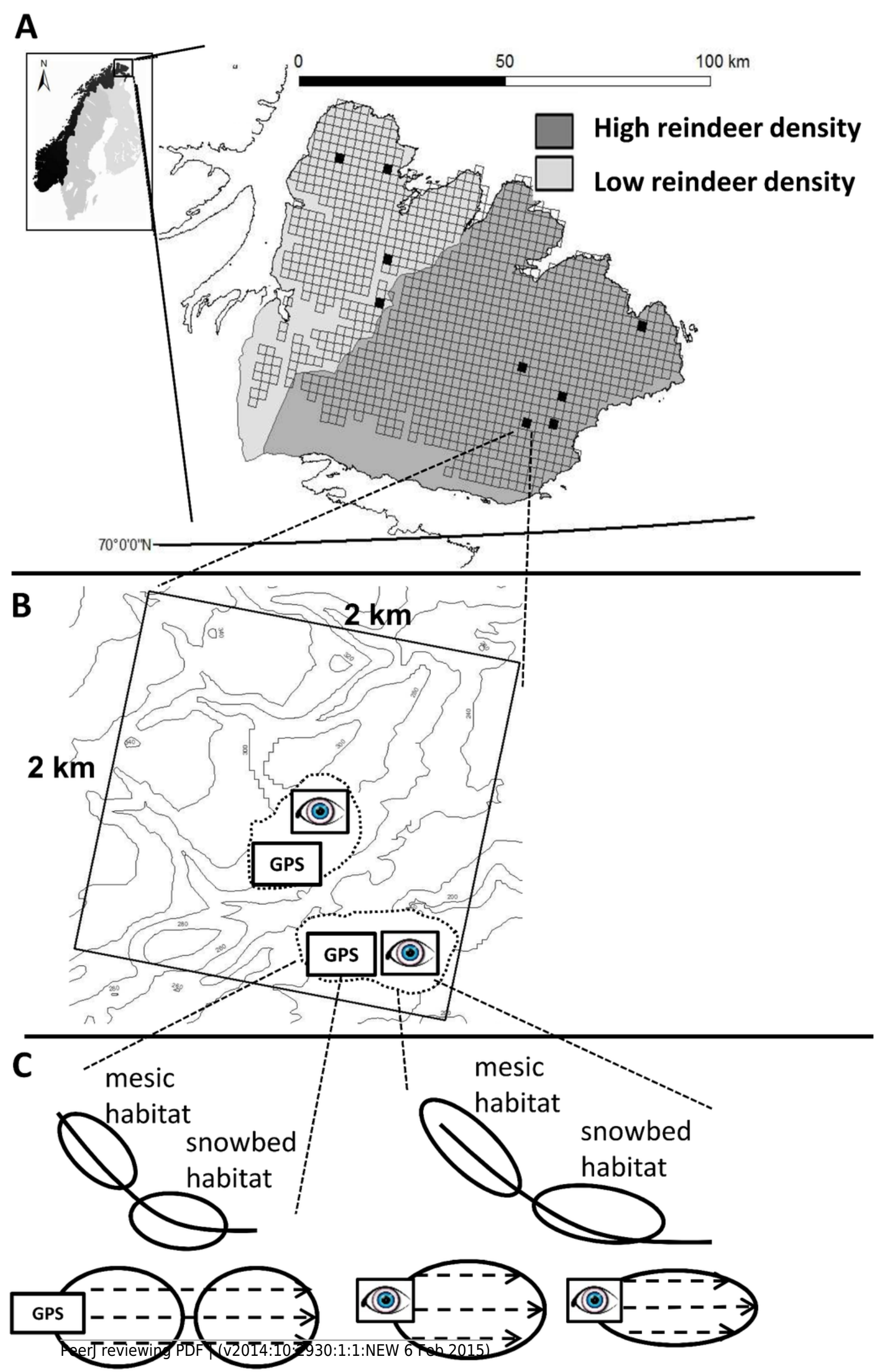




\section{2}

The figure represents all model estimates for the mesic habitat.

Effect sizes (mean $\pm 95 \%$ confidence interval) of the response difference between the subjective and the formal approach of defining sampling units within the mesic habitat are shown for estimates of diversity (A, B, C) and estimates of biomass of dominant plant species and functional groups (D). Effect sizes above or below the dotted line can be interpreted as the subjective approach having higher or lower estimates than the formal approach. Effect sizes of biomass estimates are back transformed values from a logarithmic scale, using the exponential on effect sizes from our model, and may be interpreted as the ratio of the subjective/formal approach. The numbers at the base of each figure represent estimates of the respective diversity index (A, B, C) and the geometric mean of the biomass estimates (D) from the formal approach for each respective response variable. Geometric means can be interpreted as approximate biomass estimates for the respective district. 


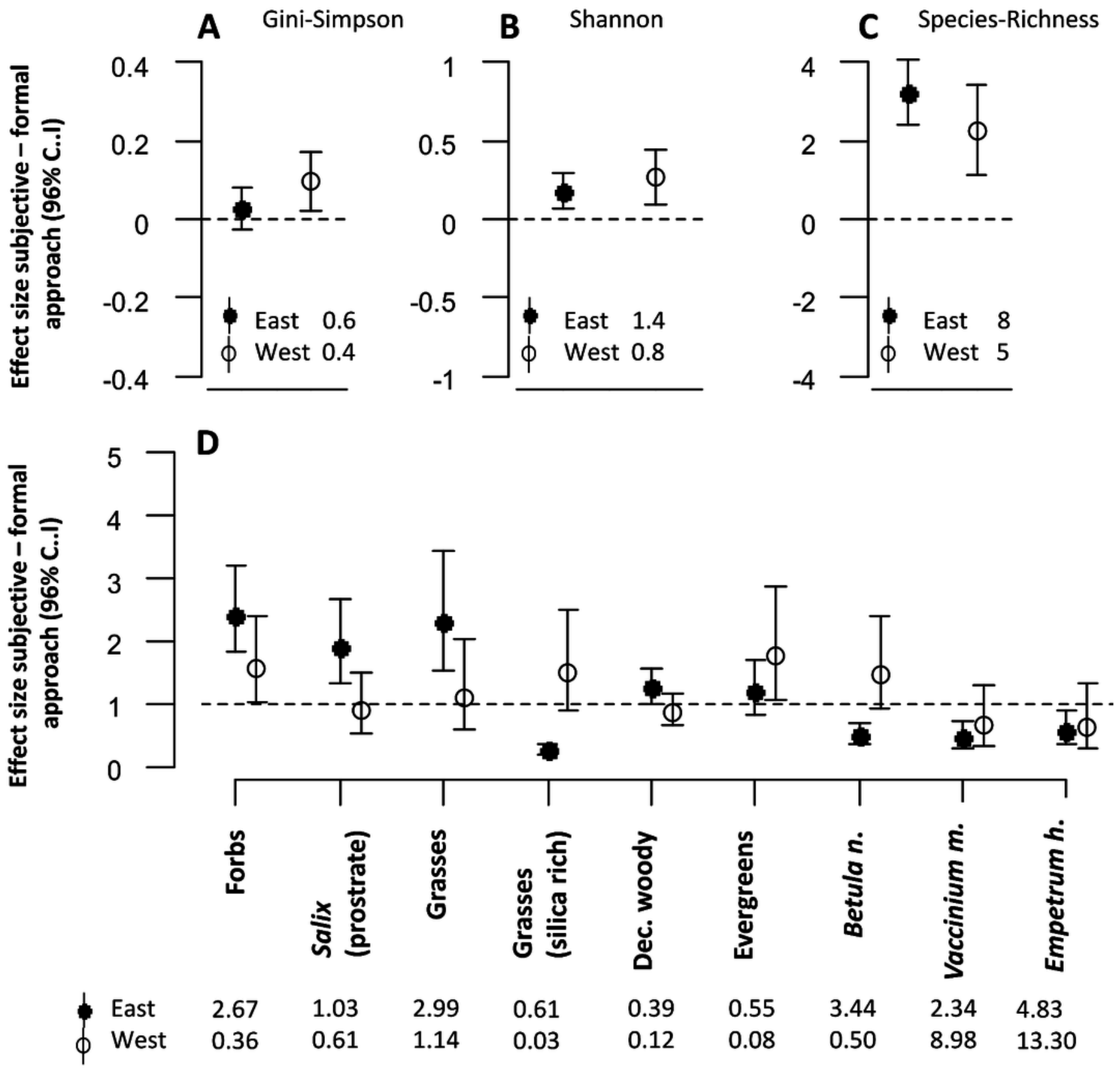




\section{3}

The figure represents all model estimates for the snowbed habitat.

Effect sizes (mean $\pm 95 \%$ confidence interval) of the response difference between the subjective and the formal approach of defining sampling units within the snowbed habitat are shown for estimates of diversity (A, B, C) and estimates of biomass of dominant plant species and functional groups (D). Effect sizes above or below the dotted line can be interpreted as the subjective approach having higher or lower estimates than the formal approach. Effect sizes of biomass estimates are back transformed values from a logarithmic scale, using the exponential on effect sizes from our model, and may be interpreted as the ratio of the subjective/formal approach. The numbers at the base of each figure represent estimates of the respective diversity index (A, B, C) and the geometric mean of the biomass estimates (D) from the formal approach for each respective response variable. Geometric means can be interpreted as approximate biomass estimates for the respective district, hence the slightly negative value for Empetrum nigrum which had very low biomass recordings in the eastern district. 


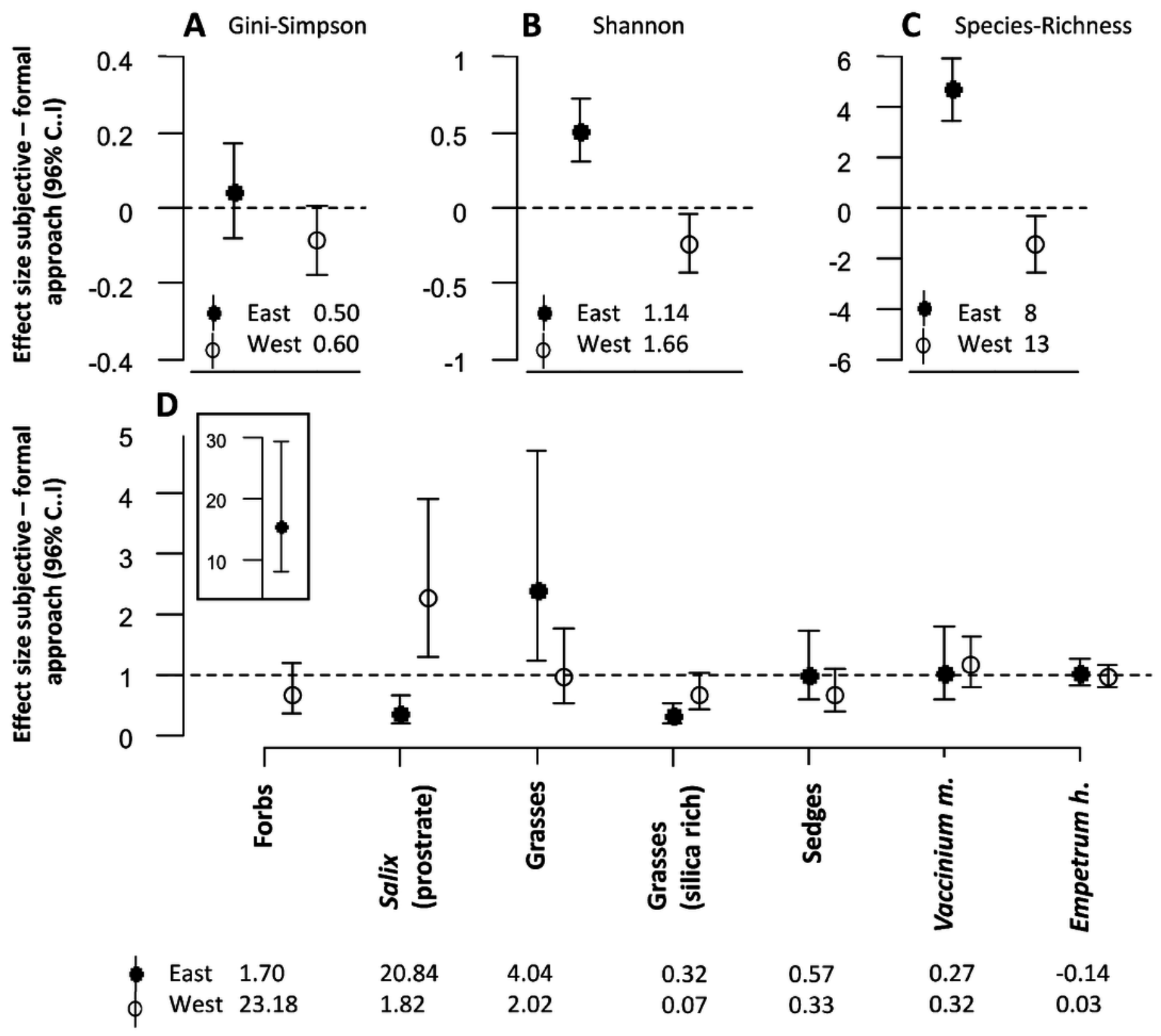

